\title{
Does Marine Lenhart Syndrome really exist?
}

\author{
Essien Francis $^{1 *}$, Jacocks Charles ${ }^{1}$, Elkins Blake ${ }^{2,3}$, Tate Joshua ${ }^{2,3}$ \\ ${ }^{1}$ Travios Air Force Base, CA; David Grant Medical Center, Department of Internal Medicine. \\ ${ }^{2}$ Keesler Air Force Base, MS; Keesler Medical Center, Department of Internal Medicine. \\ ${ }^{3}$ Keesler Air Force Base, MS; Keesler Medical Center, Department of Internal Medicine, Division of Endocrinology.
}

*Corresponding author: Essien Francis, Travios Air Force Base, CA; David Grant Medical Center, Department of Internal Medicine.

Received date: September 29, 2021; Accepted date: October 20, 2021; Published date: October 25, 2021

Citation: Essien Francis, Jacocks Charles, Elkins Blake, Tate Joshua. (2021) Does Marine Lenhart Syndrome really exist?. Archives of Medical Case Reports and Case Study, 4(5); DOI:10.31579/2692-9392/086

Copyright: (c) 2021 Essien Francis, This is an open access article distributed under the Creative Commons Attribution License, which permits unrestricted use, distribution, and reproduction in any medium, provided the original work is properly cited.

\begin{abstract}
:
Primary hyperthyroidism is the result of overproduction of thyroid hormone resulting in the classic symptoms of tachycardia, weight loss, diaphoresis, and hyperdefecation. There are multiple common causes to include Graves' disease, toxic multinodular goiter, and solitary toxic adenomas. Marine Lenhart Syndrome (MLS) is a rare cause of hyperthyroidism, caused by a coexistence of constitutively active thyroid nodules and Graves' disease. In the original document of Marine and Lenhart, there is no distinction made between the autoimmune phenomenon of Graves' disease and the solitary toxic nodule of Plummer's disease. Rather they are both considered to be the manifestation of the same disease. However, in the current era of radionuclide technology, a clear distinction of MLS can be seen with diffuse uptake in the thyroid gland and focused enhancement in the toxic nodules. Therefore what was previously described as one entity is now distinct as Graves' disease and Plummer's disease. It is also becoming increasingly clear within the literature that there is also a new phenomenon of post-radioiodine immunogenic hyperthyroidism in patients with toxic nodules and elevated autoantibodies. Therefore in order to properly treat and manage patients, a new definition of MLS may need to be proposed.
\end{abstract}

Key words: marine lenhart syndrome (mls); hyperthyroidism; radioiodine therapy; autoantibodies;

graves'disease

\section{Introduction:}

The term Marine Lenhart syndrome (MLS) has been assigned to this presentation with the coexistence of Graves' disease and toxic adenomas and has become more frequently recognized within the literature [1]. However the text by Marine in 1940 failed to appropriately distinguish these two conditions noting toxic adenoma and immunogenic goiter as one condition [1]. The syndrome as described in 1972 by David Charkes [2] based off the original observations of Marine and Lenhart [3] was defined as patients with Graves' disease and toxic adenomas that exhibit increased radioiodine uptake with TSH stimulation, appear hypofunctioning in relation to extranodular tissue on RAIU and scan, are poorly responsive to RAI ablation, and exhibit increased radioiodine uptake after RAI ablation therapy [3]. Thus, one of the key distinctions of the toxic adenomas of MLS compared to those autonomous nodules found in Plummer's disease was their TSH dependence. A recent literature review in 2011 by Biersack suggested that MLS may be a conjoined syndrome; the classical Graves' disease/toxic adenoma v Graves' disease post RAI ablation with autonomously functioning thyroid nodules [1]. Examination of the previous definition of toxic adenomas by Plummer defines hyperthyroidism as a disease caused by two separate entities (Toxic adenoma and exophthalmic goiter) [1]. Thus the original term may not apply to what we now know to be two separate diseases and the medical literature needs to be updated to reflect the origin of the joint presentation.

\section{Discussion:}

The prevalence of this syndrome has been reported to be between 2.7$4.1 \%$ of hyperthyroidism diagnoses [2], though is likely an under recognized cause of hyperthyroidism. Over the last decade there have been multiple case reports published within the literature of the manifestation of autoimmune induced hyperthyroidism following radioiodine therapy in patients with solitary toxic adenomas [1]. Thyrotoxicosis is caused by excess thyroid hormone production which can present with associated clinical findings such as tachycardia, tremor, heat intolerance, hyperdefecation, and weight loss. [2] Laboratory evaluation is typically notable for a low TSH and an elevated FT4. [2] Primary hyperthyroidism is most commonly due to Graves' disease, accounting for $60-80 \%$ of hyperthyroid cases [1,2]. Graves' disease is characterized by serum antibodies against TSH receptors in 
correspondence with $\mathrm{T}$ cell mediated immunity. Other causes such as Toxic adenomas or toxic multinodular goiters, also known as Plummer's disease, are a result of several somatic point mutations in the third transmembrane loop of the TSH receptor leading to autonomous function in absence of TSH [3]. The presence of thyroid nodules coincide with Graves' disease in 25-30\% of patients [2]. Though both disease processes result in thyrotoxicosis, their mechanism of actions are distinct (Figure 13 indicate a classical diagnostic image of MLS on both US and RAIU).

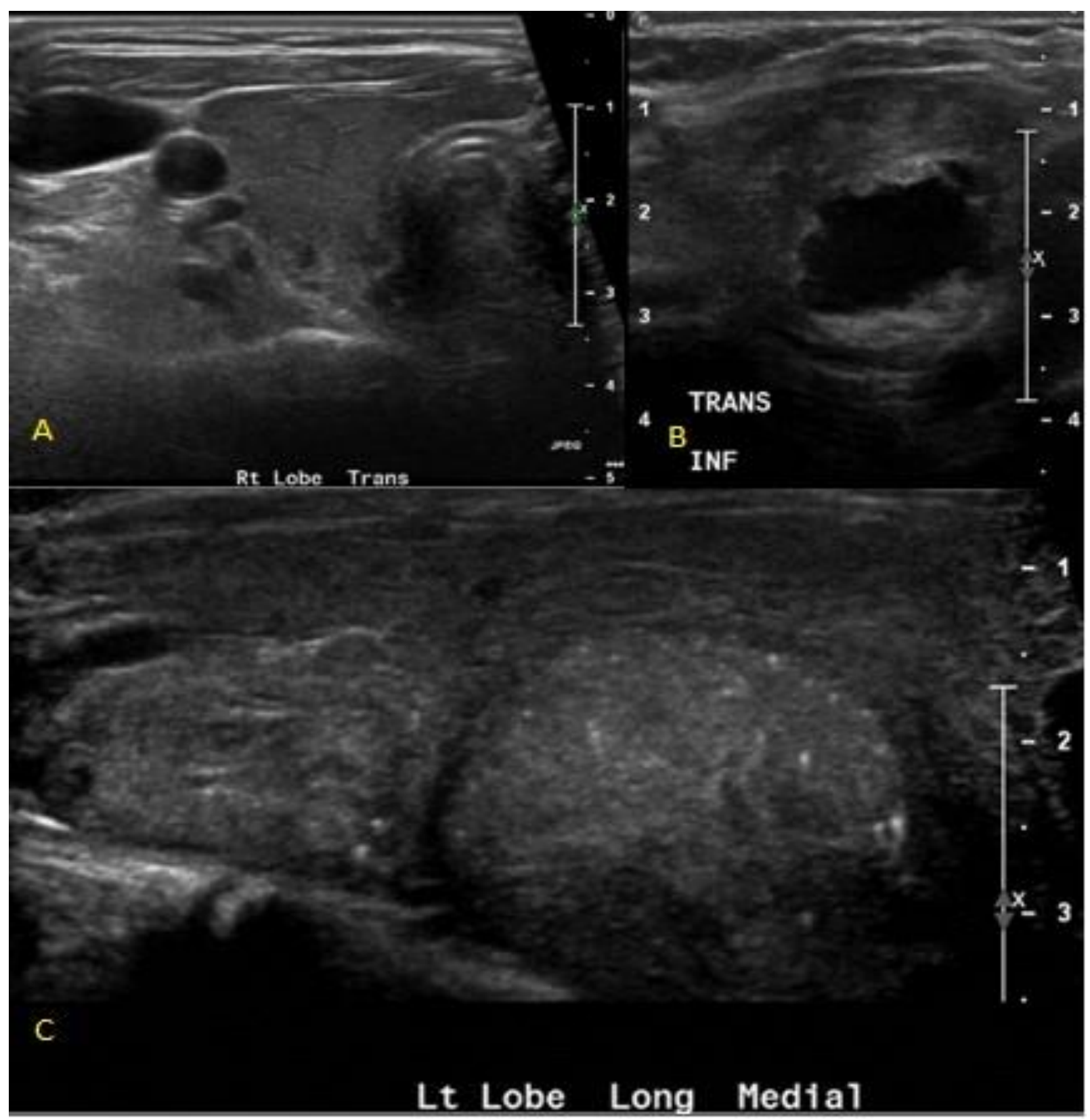

Figure 1: A. Right mid thyroid lobe transverse view; B. Left inferior thyroid lobe transverse view; C. Left thyroid lobe longitudinal view. 


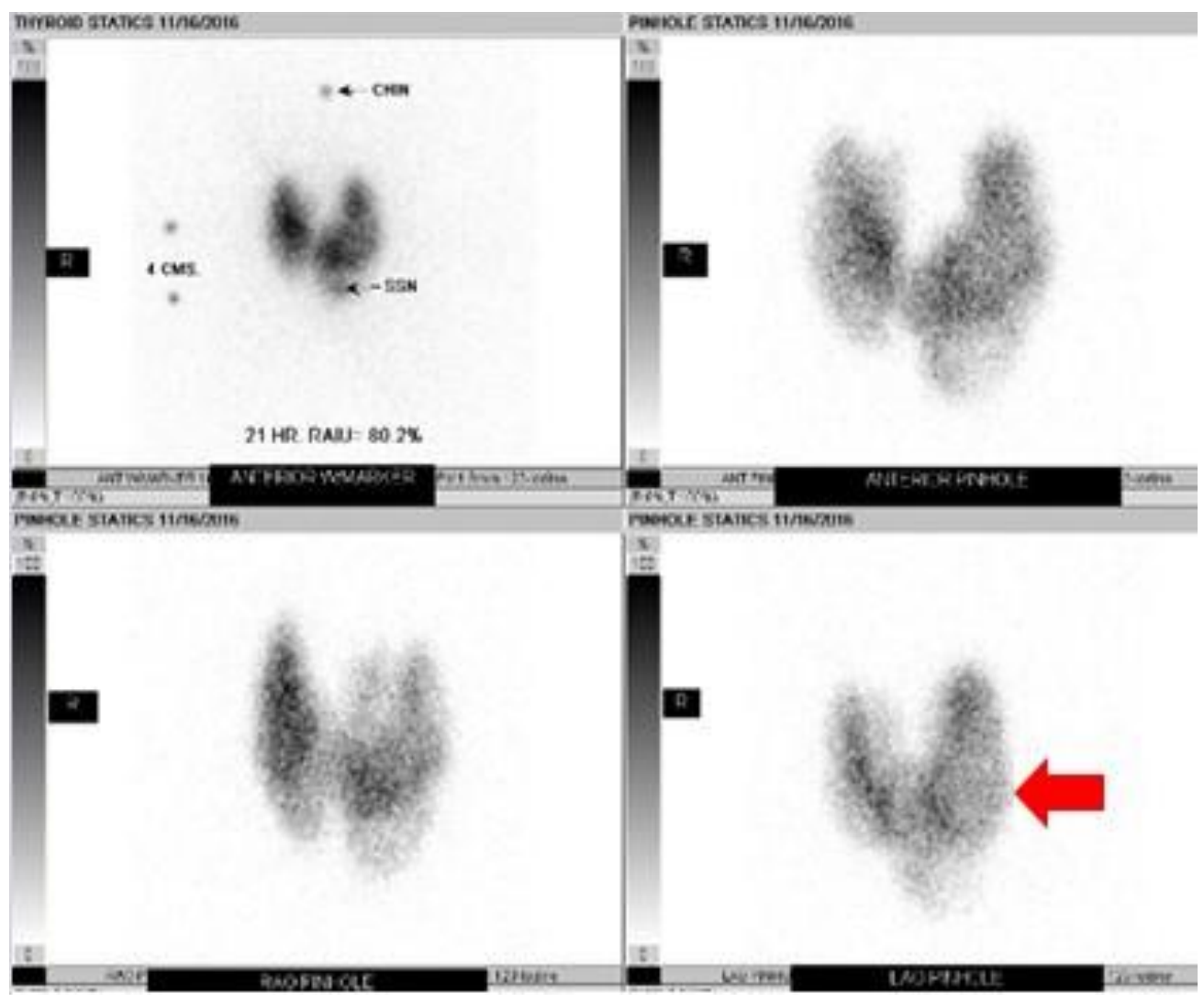

Figure 2: Multiple views of thyroid gland 21 hours after radioactive iodine-123 Administration - uptake at $80.2 \%$. Foci of decreased radiotracer uptake in left thyroid lobe (Arrow). Diagnosis: Graves' disease.

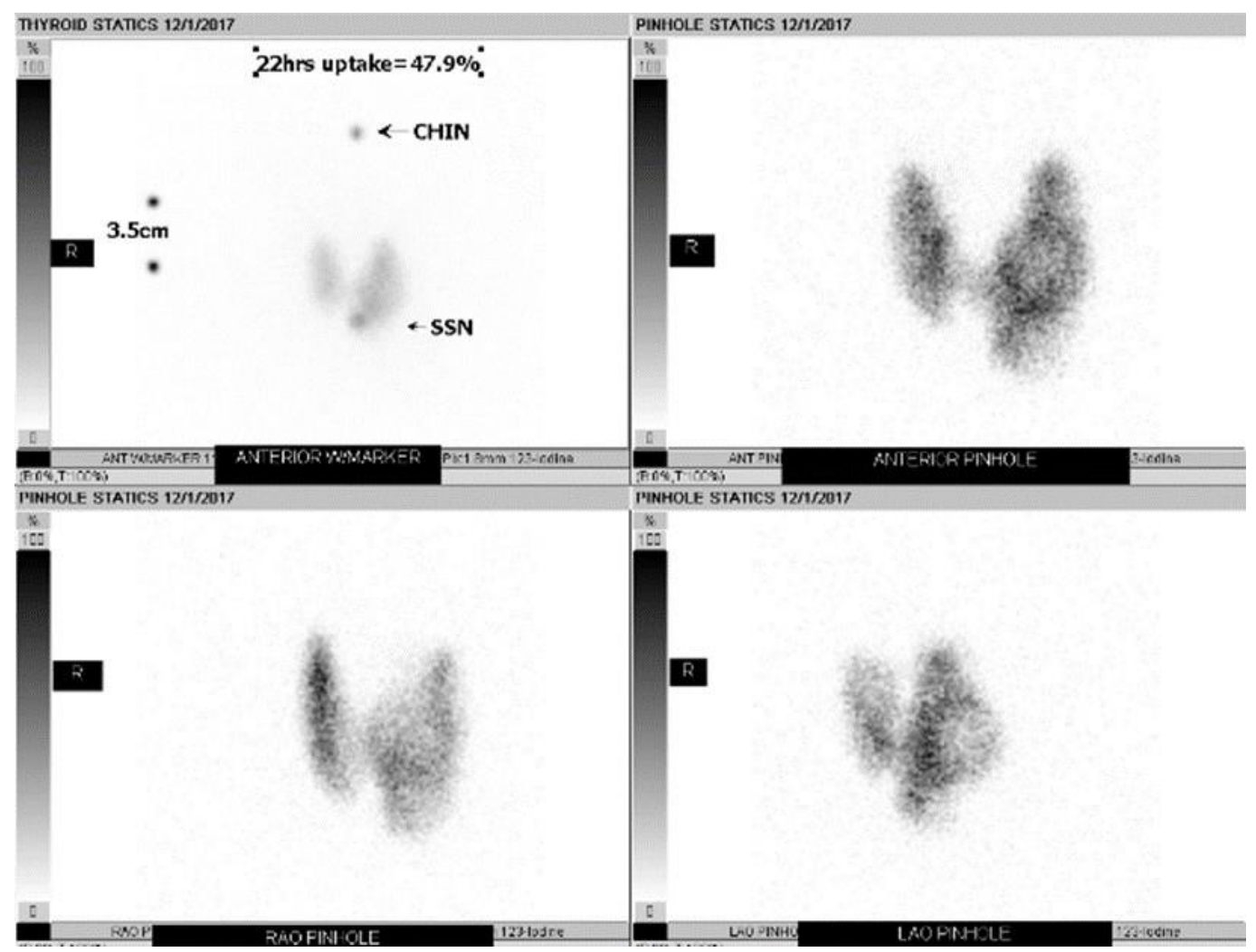

Figure 3: Multiple views of thyroid gland 22 hours after radioactive iodine-123 administration - uptake at 47.9\%. Diagnosis: toxic multinodular goiter. 
The incidence is especially high in those patients with pre-existing autoantibodies which is not unusual [2]. Due to the clonal origin of toxic nodules, activating thyrotropin receptor mutations can be present and amplify the activity of the nodule which leads to increased risk of "postradioiodine immunogenic hyperthyroidism" [3,4]. However, manifestation of this disorder does not constitute the patient as having MLS when examined from the historical definition established by David Marine and C.H. Lenhart in 1911 [1,2]. Hence there remains controversy regarding formal diagnosis due to variations in imaging techniques, presentation, and onset $[5,6]$. Thus the definition and diagnostic criteria for Marine Lenhart Syndrome have subsequently undergone multiple revisions.

Recently documented cases of MLS include cases of coexisting Graves' disease and hyperfunctioning nodules at the time of diagnosis [7-10], cases of Graves' disease with "cold" nodules at the time of diagnosis that then later were confirmed as hyperfunctioning [11], and cases of development of toxic adenomas years after successful treatment of Graves' disease [12-13]. This highlights the need for a unified definition of MLS, which was proposed by Neuman et al [7]. These proposed diagnostic criteria included confirmed hyperthyroidism based on thyroid function tests with positive thyroid autoantibodies consistent with Graves' disease, RAIU scan revealing hyperfunctioning nodules that correspond to nodules seen on ultrasound on a background of diffusely increased radioiodine uptake, and confirmation of the presence of a follicular adenoma or hyperplastic lesion on pathologic analysis [8]. Pathologic analysis is important as there have been cases reported in the literature thus far of MLS patients with the additional finding of papillary thyroid carcinoma identified in an associated nodule with the most recent being published by Mehmet et al of a unique case of papillary thyroid carcinoma in a hyper functioning nodule [14]. This definition also encouraged a transition from using the term "autonomous" nodules to describing them as functional nodules to include the subset of MLS cases with apparent TSH dependence of the associated nodules. In fact, prior proposed definitions included the requirement for the associated nodules to demonstrate TSH dependence [15]. This currently proposed diagnostic criteria allows for inclusion of the multiple identified variants of MLS to include this unique case of nodules that appeared cold on initial RAIU scan but were later confirmed as hyperfunctioning nodules on subsequent scans after completion of RAI ablation without evidence of return to a chemically euthyroid state.

Management of MLS relies on radioactive treatment or surgery with latter being preferred in the case of malignancy, large or symptomatic goiters, moderate to severe orbitopathy and patient preference [8]. Thionamide therapy can be used in select patients, such as those with severe hyperthyroidism or advanced age, to achieve euthyroidism prior to definitive therapy realizing that, although uncommon, hepatotoxicity may occur [8]. Damle et al note that the amount of radioiodine required to relieve the hyperthyroidism in these patients is greater than the corresponding mean, median or mode dose for diffuse toxic goiter thought to be a result of the large size as well as the radio-resistance of the goiters in this disease [16].

\section{Conclusion:}

Marine Lenhart Syndrome remains a rare and poorly defined entity that should be considered different both diagnostically and therapeutically from any etiology of thyrotoxicosis in isolation. A broader definition and increased awareness is needed to allow for better understanding and improved treatment guidelines for this syndrome.

All authors discussed the results and contributed to the final manuscript.

\section{References:}

1. Biersack, H., Biermann, K. (2011) The Marine Lenhart Syndrome Revisited. The Central European Journal of Medicine. 123: 459-462

2. Cakir, M. (2005) Marine Lenhart Syndrome. Journal of the national medical association. 97 (7)

3. N. D. Charkes, (1972) "Graves' disease with functioning nodules (Marine-Lenhart syndrome)" Journal of Nuclear Medicine. 885-892 (13)

4. Avci, E., Narci, H. (2015) Coexistence of Graves' disease and toxic adenoma: a rare presentation of Marine-Lenhart Syndrome. J Ayub Med Coll Abbottabad. 27 (1)

5. Brahma et al. The Oldest case of Marine-Lenhart syndrome? 2012. Journal of the Royal Society of Medicine short reports. $3(21)$

6. Marine D, Lenhart CH. (1911) Pathological Anatomy of Exophalmic goiter - The anatomical and physiological relations of the thyroid gland to the disease; the treatment. Arch Int Med. 265-316 (8)

7. Cakir M. (2005). Marine-Lenhart syndrome. J Natl Med Assoc. 97(7):1036-1038.

8. Neuman D, Kuker R, Vendrame F. (2018). Marine-Lenhart Syndrome: Case Report, Diagnosis, and Management. Case Rep Endocrinol. 3268010

9. Scherer T, Wohlschlaeger-Krenn E, Bayerle-Eder M, et al. (2013) A Case of simultaneous occurrence of Marine - Lenhart syndrome and a papillary thyroid microcarcinoma. BMC Endocr Disord. 13 (16)

10. Miyazaki M, Okada Y, Torimoto K, Tanaka Y. (2019) A Case of Marine-Lenhart Syndrome with Predominance of Plummer Disease. J UOEH. 41(2)

11. Brahma A, Beadsmoore C, Dhatariya K. (2012) The oldest case of Marine-Lenhart syndrome?. JRSM Short Rep. 3(4)

12. Waldherr C, Otte A, Haldemann A, Müller-Brand J. (1999) Das Marine-Lenhart-Syndrom: Eine Fallbeobachtung über 18 Jahre [Marine-Lenhart syndrome: a case observation upon 18 years]. Nuklearmedizin. 38(8)

13. Giuffrida G, Giovinazzo S, Certo R, et al. (2014) An uncommon case of Marine-Lenhart syndrome. Arq Bras Endocrinol Metabol. 58(4)

14. Mehmet et al. (2016) A Rare Presentation of Autonomously Functioning Papillary Thyroid Cancer: Malignancy in MarineLenhart Syndrome Nodule. Case Reports in Surgery.

15. Harisankar CN, Preethi GR, Chungath BB. (2013) Hybrid SPECT/CT evaluation of Marine-Lenhart syndrome. Clin Nucl Med. 38(2)

16. N. Damle and R. Mishra, "Identifying Marine-Lenhart syndrome on a $(99 \mathrm{~m}) \mathrm{Tc}$-pertechnetate thyroid scan," Indian Journal of Endocrinology and Metabolism, vol. 17, no. 2, 366 pages, 2013. 
This work is licensed under Creative Commons Attribution 4.0 License

To Submit Your Article Click Here: Submit Manuscript

DOI: $10.31579 / 2692-9392 / 086$
Ready to submit your research? Choose Auctores and benefit from:

$>$ fast, convenient online submission

$>$ rigorous peer review by experienced research in your field

$>$ rapid publication on acceptance

$>$ authors retain copyrights

$>$ unique DOI for all articles

> immediate, unrestricted online access

At Auctores, research is always in progress.

Learn more auctoresonline.org/journals/archives-of-medical-casereports-and-case-study 